\title{
SOCIAL DIAGNOSIS IN EDUCATIONAL WORK. DEVELOPMENT, TRANSFORMATIONS - MODERN CHALlenges. Social PEDAgOgY CONTEXT
}

\begin{abstract}
The aim of the article is to identify the development of the concept of social diagnosis that took place and takes place in social pedagogy. In this discipline, from the very beginning of its existence, the concepts of environmental diagnosis were developed as an activity preceding the necessary social action changing - improving the social world. The area of research are the concepts of social diagnosis developed in social pedagogy by the main creators of this discipline - from the beginnings of its existence up to modern times. The analysis of reconstructed concepts shows that the social diagnosis undertaken in social pedagogy applies to both individuals and social groups - it identifies the environmental conditions of their life and functioning. Most often it concerns such areas as social conditions, participation in culture but also educational conditions and possibilities. It would be necessary to deepen the social diagnosis - also in the sphere of psychological experiences of the participants of social life and the level of their life - also showing new educational environments and their determinants.
\end{abstract}

KEYWORDs: education, social education, diagnosis, environment, individual, group

\section{INTRODUCTION}

The notion of diagnosis in educational work is a key issue especially from the perspective of a proper educational practice. It is the proper recognition of the areas and space in which educational activities occur, what may guarantee their proper conduction. Considering the role of social conditionings in 
the upbringing process - assuming their crucial and decisive role in the process - the notion of diagnosis has been most widely developed within social pedagogy. The assumptions made in this area may be a valuable and helpful tool for teachers, pedagogues or caretakers engaged in the upbringing process.

Therefore, the attempt to describe the shaping of the concept of diagnosis in social pedagogy requires an insight into the basic and rudimental idea assumed in this discipline; the idea the discipline stems out of; the idea which describes it on every level, e.g.: creating theories and concepts, undertaking and realizing particular activities including diagnostic activities.

This basic and rudimental idea, which may be found in social pedagogy, regardless of any theoretical and methodological current, is that it presents and studies a human being entangled in certain environmental relationships which determine any practical activities - suggested in social pedagogy. A human, remaining in a relationship with the environment which, on the one hand, influences and determines its functioning and, on the other hand, is formed by a human - is the starting point, the rudiment for social pedagogy. It is relatively stable when it comes to the specificity of the discipline. Whereby, it is noteworthy that any interactions and relationships mentioned within social pedagogy are always of educational character, namely: upbringing, nursing and social aid or, differently, animation, education etc. Such understanding of social pedagogy may be depicted by one of many modern definitions of this discipline that are cited in scientific analyses. Thus, in one of his works, W. Theiss coined the following characteristic of the subject of social pedagogy: "Social pedagogy deals with the theory of environmental conditionings of human education and development as well as the theory and practice of shaping the environment. This context includes social work and cultural work which are treated as forms of transforming environment" (Theiss, Przecławska, 1996, p. 9). A similar, yet expressed in a different theoretical and conceptual context, definition was coined by Stanisław Kawula, who claims that "Social pedagogy focuses on the notions regarding environmental conditionings of educational processes as well as on the analysis of the conditions (factors) which allow for satisfying the human (social groups) developmental needs at different stages of their lives and various life situations" (Kawula, 1996, p. 29). 
The starting point for social pedagogy described in this way, significantly and fundamentally determines the whole process of diagnosis which is suggested within this discipline. Diagnosis always, especially in social sciences, has its addressee, is undertaken in a specific context and under particular conditions. It has its clear aim and specific methods of realization. All these aspects are always related to and proper with the discipline and the course of thinking and elaborating it assumes.

Henceforth, it is interesting how the understanding of (social) diagnosis developed within social pedagogy, how it was realized and determined in the light of the abovementioned assumptions.

\section{THE DEVELOPMENT OF THE CONCEPT}

Starting with the presentation of the views of Helena Radlinska - the creator of Polish social pedagogy, it ought to be stated that she was the person who suggested borrowing the notion of diagnosis from medicine to social pedagogy. At the very beginning of the shaping of this discipline, Radlińska acquired a very simple way of understanding diagnosis i.e. "distinguishing the causes of the particular examinee's condition, determining their symptoms and possibilities of transformation" (Radlińska, 1961, p. 370). Simultaneously, she noticed what became a specific outline of diagnostic activities in social pedagogy from that point on, that "establishing diagnosis leads to planning activities which are aimed to strengthen the examined individual or group, set their will to overcome evil and provide external aid" (Radlińska, 1961, p. 370). This requirement to transfer diagnosis onto specific activities aiming to change the current status quo has become the specific outline of thinking about diagnosis in social pedagogy. The whole understanding of diagnosis by Helene Radlińska was supplemented by her definition of prophylactics and compensation. She claims that: "Social prophylactics involves preventing social crises and demoralization of individuals. It is frequently connected with medical prophylactics (preventive medicine). The most important areas of prophylactics are: combating intemperance, prostitution, crime, infectious diseases, homelessness" (Radlińska, 1961, p. 370). Simultaneously, "compensation accounts for deliberate covering up deficiencies, supplementing or substituting unfavourable components of 
personal or group situation and creating life conditions regarded as normal" (Radlińska, 1961, p. 371).

Being a practitioner, Helena Radlińska did not devote a lot of her scientific attention to developing a precise and extensive concept of diagnosis. She remained at the level of the presented establishment. It is noteworthy that, at the stage of recognising social reality where the whole process of diagnosis begins, the author clearly settled herself within the current of empirical research model following the patterns of the scientific pedagogy of that time. She supported the perspectives of, e.g. J.W. Dawid or St. Karpowicz who represent Polish empirical pedagogy as well as the representatives of the German current such as: P. Barth, P. Natorp or H. Hetzer from whom she drew the whole model of environmental pedagogical studies (Cichosz, 2003).

Another important and key figure in social pedagogy - Ryszard Wroczyński devoted more attention to the concept of diagnosis in his scientific works. The author followed the basic, rudimental ideas of social pedagogy and emphasized the fundamental role of environment in human life. Unlike Helena Radlińska, who inclined the practice of social pedagogy towards social work and aid, Ryszard Wroczyński built the environmental concept of social pedagogy which slightly drifted from social work and aid. He claimed that: “... Social pedagogy is interested in those wider circles of pedagogical influences which occur outside school in the life environments of the pupils, in the circle of contacts with material system, with cultural achievements. Social pedagogy extends the notion of planned educational activity on actions which are aimed to control the social environment, organize coexistence and social cooperation, participation in social, economical and cultural institutions" (Wroczyński, 1971).

Ryszard Wroczyński sees the environment as a set of factors which decide about the development of every person. Therefore, any pedagogical work ought to be preceded by a diagnosis of environmental conditions, a diagnosis which may answer to what extent and direction the environment influences an individual. In this respect, a problem of measuring environmental conditions arouses. Only a precise measurement of environmental conditions allows for intervention activities in the environment which had already been stated by Helena Radlińska to be the primary outline of social pedagogy. Consequently, 
the need for diagnosis of environmental conditions was one of the factors initiating the need for developing methodology of social environmental studies. In this respect, Ryszard Wroczyński drew on the ideas of Helena Radlińska but was also inspired by the French and English methodology of that time. He followed the environmental studies methodology by Ferdynand Le Play or Charles Booth. It is noteworthy, however, that Ryszard Wroczyński remained closely related to positivism and scientism in his approach to the model of environmental studies. The author connects diagnosis with two other aims of social pedagogy: prophylactics and compensation. He understood prophylactics as “... activity connected with preventing potential risk factors. These factors may stem out of the psychosomatic structure of a human, from their personality traits. They may result from social relationships entailing potential possibilities of influences which are contrary to the interest of a pupil" (Wroczyński, 1971, p. 32).

On the other hand, the author defined compensation as "covering up for factors limiting the development or covering up for situations resulting from unfavourable developmental conditions" (Wroczyński, 1971, p. 33). It ought to be remembered that the author clearly connected prophylactic and compensation activities with the area of school and social, upbringing and educational institutions. Wroczyński explained that "the problems of prophylactic and compensation appear [...] in extra-school environment, in the works aimed to popularize education, culture, in the realization of social care and aid tasks, in health education, in organizing an upbringing (educational) environment" (Wroczyński, 1971, p. 33).

Thereupon the issue of diagnosis as well as prophylactic and compensation activities, in view of R. Wroczyński, was related to the need for measuring environmental conditions i.e. building up methodology of environmental studies on the one hand and, simultaneously, clearly determined (limited) the research area including potential areas of practical influences to the sphere of caretaking, upbringing, education and culture mainly through extra-school institutions. It has become a visible tendency in social pedagogy up to present times.

Another creator of social pedagogy, Aleksander Kaminski, accepted the basic assumptions of this discipline i.e. the key role of environment for human development and pointed out the significant role of social diagnosis 
in the process of recognizing and transforming the human life environment. The author adopted the very definition of diagnosis from M. Richmond i.e. from the sphere of social services practice where it is used with regards to an individual and their environmental context - especially family, school, workplace, neighbourhood for these places are meant to be considerably decisive for a human fate. The social diagnosis itself "is used for determining the cause of the unfavourable conditions of a unit - their social maladjustment behaviour disorders, demoralization, social degradation" (Kamiński, 1982, p. 68). According to the established tradition and accepted model in social pedagogy, the environmental conditions diagnosis is directly transferred to particular practical activities aimed to change the unfavourable human life conditions. Following this model, Aleksander Kamiński distinguished three types of social diagnosis respectively and adequately to three methods of social-educational work in an environment. They are: 1. A particular case diagnosis aimed to recognise the causes of the problems of a given person, 2. Social groups diagnosis aimed to recognise the difficulties encountered during educational, cultural and social activity in small social groups, 3 . local societies diagnosis aimed to determine the basic needs of a local environment and distinguish various social forces apt to contribute to activities which may increase the current state (Kamiński, 1982, pp. 68-74). The measuring means for the particular case diagnosis is an interview, for the social groups diagnosis - sociometric examination while, for local societies diagnosis - social survey.

It is noteworthy that according to Aleksander Kamiński’s concept there are three clear areas of activity, hence three areas that undergo social diagnosis aimed to determine their actual state $=$, namely: individuals, groups, social institutions in their environmental circumstances. It is a typical yet narrow approach to social pedagogy. The whole idea is to distinguish the socioeducational possibilities of changing (melioration) human behaviour and the functioning of institutions which is to be obtained through compensating the acknowledged deficiencies, providing proper forms of care and prophylactic support for the development of people and institutions. It is also important in Aleksander Kamiński's concept that compensation and prophylactic activities are not undertaken with regards to psychic but they are external acts toward an individual - they are planned environmental procedures. Example 
compensation activities are e.g. a foster family, a youth club or a nursing home whereas sample prophylactic may be the activity of such institutions as a kindergarten, a day-care club, a scout team etc. The concept of Aleksander Kamiński, concordant with the idea of social pedagogy, accentuates a very important notion related to the whole sphere of environmental endeavours including social diagnosis which is the role of social forces, their recognition and use in the organization of environment. It is especially significant with regards to the possibilities of transforming social reality.

\section{CONTEMPORARY CONDITIONINGS}

All of the settlements presented above with regards to the understanding of diagnosis in social pedagogy, coined by its creators Helena Radlińska, Ryszard Wroczyński and Aleksander Kamiński, have been adopted by contemporary social pedagogues who constantly broaden and develop the notion.

A contemporary representative of social pedagogy - Stanisław Kawula draws on the works of its creators describing the notion of diagnosis. The author emphasizes the environmental context of functioning of individuals and groups and claims that the diagnosis is about "orientating our recognition towards those social conditionings of situations and fate of individuals and groups which closely surround them, mainly in family, school, workplace, home and peer group. Therefore, pedagogical diagnosis always has a social aspect as it seeks the cause of particular state of human behaviour, state of functioning of social groups or institutions in their mutual relationships and influences” (Kawula, Dąbrowski, Gałaś, 1980, pp. 41-42). Regarding an individual, however, pedagogical diagnosis ought to estimate whether or not the examined level of developmental properties of a pupil and their personality conforms with the aims of education, nursing, cultural life etc. It is also meant to determine the level and the causes which formed these properties. Therefore, the tasks of pedagogical diagnosis ought to be analyzed with reference to the regularity of the bio-psycho-social development of a person. It is a very clear reference to the concept of a human coined by Helena Radlińska at the very beginning of social pedagogy which sees the human as a bio-socio-cultural unity whose development occurs at three levels and layers. Ultimately, Stanisław Kawula distinguished the following 
basic factors (areas) that should undergo diagnosis with respect to the need for undertaking pedagogical activities:

- Material factors, e.g. a network of particular institutions and devices in the environment, communication and settlement conditions of the closest region, geographic-natural conditions, the state of public and individual social benefits, the network of services.

- Psychopedagogical factors, e.g. the kind of emotional bond in a nursing institution, the forms of work in a cultural institution, the possibility to realize the nursing role by school, the activity of a community day-care centre, the pedagogical culture of parents, the qualifications of teachers, the effectiveness of the work of a youth organization.

- Socio-cultural factors, e.g. the culture of interpersonal relationships in a particular situation, the attitude of parents towards school, the customs and traditions existing in the environment, the kind of neighbourhood bond, the functions of social control in the place of residence, the forms of artistic activity, the attitudes towards people with disabilities, the kind of participation in cultural life.

- The organization of life in the environment, e.g. the notion of cultural life coordination, the existence and activity of various self-government forms, social events for the community, various displays of social forces activity, the functioning of health service and social service (Kawula, Dąbrowski i Gałaś, 1980, p. 67).

In order to determine the level of human development according to Stanisław Kawula's concept, it is necessary to consider the significant role of upbringing, nursing and cultural needs for their fulfillment is an indicator of the development of an individual. Therefore, "a significant problem of pedagogical diagnosis is not only to determine (recognise) the very needs and fulfil them in a particular environment but also to analyze the situations which evoke certain deficits in occurring, regulating and satisfying particular needs. It is especially worthwhile for the aim and notion of pedagogical diagnosis of an environment to recognise the situations which bring about particular deficits or threats regarding the regulation and fulfillment of individual and social needs" (Marynowicz-Hetka, 1987, p. 47). 
Another concept of pedagogical diagnosis which remains concordant with the beliefs of the first creators of the notion, especially Helena Radlińska and Aleksander Kamiński, is the understanding of pedagogical diagnosis suggested by Ewa Marynowicz-Hetka. The author sees diagnosis as an activity related to socio-educational work. Simultaneously, she understands socio-educational work as an activity aimed to aid the development which is oriented towards individuals, groups and communities. Moreover, following the accepted specificity of social pedagogy, this activity proceeds to transform the environment in such a way that a pupil - participant of social life develops according to the standards of development. The author understands development as "a directed process of transformations which proceed through particular phases aiming to achieve higher structural and functional forms" (Lepalczyk i Marynowicz-Hetka, 1988, p. 19). The socioeducational activity, which is the rudimental activity in the concept of social pedagogy according to Ewa Marynowicz-Hetka, ought to be carried out with the use of three methods of socio-educational work in an environment. Such an approach conforms with the tradition of social pedagogy elaborated earlier (conf. A. Kamiński) and involves the method of individual cases, method of working with a group and the method of organizing environment. The socio-educational activity realized through these three methods is supposed to support the development of an individual in three spheres of their activity: biological, social and cultural i.e. the areas of growth, rise and implementation (introduction) with reference to the concept by Helena Radlińska. The presented socio-educational activity in an environment should be preceded by diagnosis - recognition of resources (social forces of the environment). The presented concept, also with regards to diagnosis, emphasizes the key role of the category of socio-educational institutions as through their activities the three functions of social pedagogy may be fulfilled: aid in bio-socio-cultural development, compensation for individual and environmental deficits as well as educational prophylactics.

Among the contemporary representatives of social pedagogy interested in diagnosis is Ewa Wysocka. The author accentuates the significant role of social-environmental life in her understanding of pedagogical diagnosis and adopts a relatively wide - multidiscipline approach to this notion. She locates 
the development of diagnosis on a wide ground of social sciences (psychology, sociology and pedagogy) and defines it as "a complex process of activity which leads to a description of the results of studying a particular sample of social or individual reality achieved through an appraisal of empirical data collected from various sources (a studied person, its surrounding, diagnostician). The description involves a hypothetical characteristic of the complex status quo which is the subject of the researchers' interest, an identification and explanation of its genesis, an appraisal of its significance and determination of its developmental phase; it also accounts for the estimation of its further development and possibilities of transforming the status quo in order to optimise or eliminate developmental distortions" (Wysocka, 2013). Understood as such, modern social diagnosis serves multifarious functions such as: descriptive, explanatory, evaluative, utilitarian, optimizing, verifying, prognostic as well as expressive-therapeutic (Wysocka, 2013, p.77). The author draws attention to the concern of the competence of the diagnostician and the normative-axiological dimension of this process. She claims that "Diagnosis in pedagogy is not an axiologically neutral discipline. For instance, the recognition carried out as part of it includes not only descriptive-explanatory but also appraisal or valuating conclusions" (Wysocka, 2013, p. 300).

The presented analyses prove that a very important area and, simultaneously, a rudimental (in an existential sense) point of reference in social diagnosis is environment. It is the space of human functioning which conditions the functioning at the same time. It is also the area where the upbringing process occurs so it may be regarded as the space of planned and undertaken educational activities. Pedagogy is especially interested in the upbringing environment as a place which is a particular carrier of upbringing. There is a relatively wide distinction concerning the identification of these environments in pedagogy including social pedagogy. Therefore, apart from the traditional upbringing environments like e.g. family or school, "new" upbringing environments are sought and acknowledged in the functioning of various institutions, media (traditional and modern) or various social manifestations of the functioning of local communities.

The area of these environments remains an important field for social diagnosis which assumes answering such questions like: 
- How and where do modern upbringing environments function? What are the criteria of their recognition (e.g. the types of influences, the received content...)? What is the gist of their influence?

- How to comprehend the results of their influence in the psycho-physical human structure?

- Is it possible to have impact on and transform these environments and in what form?

Concerning the proper quality of pedagogical practice, its preparation and organization ought to require the people who are to carry out and realize it to hold:

- knowledge about the upbringing environment and its regularities,

- consciousness of the variety of upbringing environments and the transformations they undergo,

- the awareness of the existence of "new" upbringing environments (places and social spaces where upbringing occurs),

- the ability to exploit educational advantages of these environments, the awareness of their chances and threats (e.g. the Internet - is it only a threat or also a chance),

- the ability to arouse the attitude of creativity presence and engagement in educational work in a particular environment.

\section{Conclusion}

Summarizing the development and ways of understanding diagnosis in social pedagogy presented through the concepts coined by several chosen yet representative figures of this notion, it is possible to indicate certain common features of these views. They may be regarded as such elements of the concept which are the effect of its development.

Firstly, diagnosis in social pedagogy always concerns human - individual or social groups. Whereby, like in social pedagogy, the suggested addressee of any activities regarding diagnosis are humans at every stage of development i.e. children, adolescents, adults and seniors. Furthermore, diagnosis in social pedagogy is a diagnosis of specific social - environmental conditions as they account for a primary layer of human development. Ultimately, 
diagnosis mainly concerns the sphere of upbringing, nursing, aid, culture and education as well as human activity in these areas. Therefore, diagnosis in social pedagogy is often described as social and pedagogical diagnosis. Similarly, it is characteristic that diagnosis, as presented in this article, is a diagnosis of institutions which realize main nursing, social, cultural and educational tasks.

The diagnosis in social pedagogy transfers to particular activities and directives of practical conduct. This, in turn, is related to the primary outline of social pedagogy which is always aimed at particular activity - transformation of the existing social reality. Therefore, diagnosis always implicates or leads to particular prophylactic or compensation activities.

The social and pedagogical diagnosis used in social pedagogy seems to undertake the notion of personal development to a relatively small extent. It is mainly oriented towards the development of methods for measuring the upbringing environment and its "elements" and focuses mainly on organizing proper institutional activities.

\section{References:}

Cichosz, M. (2003). [Polish] Social pedagogy triptych. Deliberations at the turn of ages, in: "Social pedagogy", vol. 3, Warsaw, ISSN 1642-672X.

Kawula, S. (1996). [Polish] Social pedagogy studies. Olsztyn: Wyższa Szkoła Pedagogiczna. ISBN 838551371X.

Kamiński, A. (1982). [Polish] The functions of social pedagogy. Warsaw: Państwowe Wydawnictwo Naukowe, ISBN 8301017058.

Kawula, S., Dąbrowski, Z., Gałaś, Z. (1980), [Polish] Diagnosing nursing-educational and cultural needs of the environment. Torun: Uniwersytet Mikołaja Kopernika.

Jarosz, E., Wysocka, E. (2006). [Polish] Psycho-pedagogical diagnosis. Basic concerns and solutions. Warszawa: Wydawnictwo Akademickie “Żak” Teresa i Józef Śniecińscy, ISBN 838950152X.

Lepalczyk, J., Marynowicz-Hetka, E. (1988). [Polish] Socio-educational institutions. Chosen theoretical concerns, in: [Polish] J. Lepalczyk, E. Marynowicz-Hetka (ed.) Institutional aid for a child and family. Diagnoses and propositions, WrocławWarszawa-Kraków-Gdańsk-Łódź: Zakład Narodowy im. Ossolińskich, ISBN 8304026252 . 
Marynowicz-Hetka, E. (1987). [Polish] Pedagogical diagnostics in a social-educational work, in: [Polish] J. Lepalczyk (ed.) The elements of pedagogical diagnostics, Warsaw: Państ. Wydaw. Naukowe, ISBN 8301079932.

Radlińska, H. (1961). [Polish] Social pedagogy exam. Review of the lectures, in: [Polish] R. Wroczyński and A. Kamiński, Pedagogical writings, vol. 1. Social pedagogy, introduction Text compilation and commentaries: W. Wyrobkowa-Delawska. Wrocław: Ossolineum.

Theiss, W., Przecławska, A. (1996). [Polish] Social pedagogy - new tasks and chances, in: [Polish] A. Przecławska (ed.) Social pedagogy, circles of exploration. Warsaw: “Żak”, ISBN 8386770317.

Wroczyński, R. (1971). [Polish] Social pedagogy, its basic notions and development. in: [Polish] Social pedagogy and social policy studies. Warsaw: Towarzystwo Wolnej Wszechnicy Polskiej.Wysocka, E. (2013). [Polish] Pedagogical diagnostics. New areas and solutions. Kraków: Oficyna Wydawnicza Impuls. ISBN: 9788375879094, 9788375879056. 
